Tohoku J. Exp. Med., 2008, 215, 1-11

\title{
Quantifying Nanomolar Levels of Nitrite in Biological Samples by HPLC-Griess Method: Special Reference to Arterio-Venous Difference in vivo
}

\author{
Takaharu Ishibashi, ${ }^{1,2}$ Tomoko Miwa, ${ }^{2}$ Ikumi Shinkawa, ${ }^{2}$ NaOki Nishizawa, ${ }^{2}$ \\ Minoko Nomura, ${ }^{2}$ Junko Yoshida, $^{2}$ Tomie Kawada ${ }^{3}$ and Matomo Nishio ${ }^{2}$ \\ ${ }^{1}$ Department of Pharmacology, School of Nursing, Kanazawa Medical University, Ishikawa, Japan \\ ${ }^{2}$ Department of Pharmacology, School of Medicine, Kanazawa Medical University, Ishikawa, Japan \\ ${ }^{3}$ Department of Clinical Pharmacy, Faculty of Pharmacy, Musashino University, Tokyo, Japan
}

\begin{abstract}
Nitrite $\left(\mathrm{NO}_{2}{ }^{-}\right)$is assumed to play an important role in regulation of vascular tone as a reservoir of nitric oxide (NO). To examine its physiological contribution, however, a sensitive method is required for determination of the true level of $\mathrm{NO}_{2}^{-}$in biological samples. To this end, practical consideration to avoid $\mathrm{NO}_{2}{ }^{-}$contamination through the quantification procedure is important. We present here a highly sensitive and accurate method for determining $\mathrm{NO}_{2}{ }^{-}$in plasma by improving the HPLC-Griess system with minimal $\mathrm{NO}_{2}{ }^{-}$contamination in the samples. The system achieved high sensitivity (detection limit of $2 \mathrm{nM}$ and sensitivity to $1 \mathrm{nM}$ ) and complete separation of the $\mathrm{NO}_{2}{ }^{-}$signal peak by modifying the system setup and mobile phase. Using this method, we achieved acceptable quantification of low $\mathrm{NO}_{2}{ }^{-}$levels in plasma. Deproteinization by ultrafiltration and exposure to atmosphere before measurement were identified as the major sources of $\mathrm{NO}_{2}^{-}$contamination during sample processing. We addressed these issues by the use of methanol for deproteinization and gas-tight caps. These countermeasures allowed us to detect small arterio-venous $\mathrm{NO}_{2}{ }^{-}$ differences in rabbit plasma that may indicate kinetic difference of $\mathrm{NO}_{2}^{-}$in a small number of samples $(n=6)$. This difference became prominent when $\mathrm{NO}_{2}{ }^{-}$or a $\mathrm{NO}$ releasing agent, NOR1, was intravenously applied. Our results indicate that application of a sensitive method with careful handling is important for accurate determination of $\mathrm{NO}_{2}{ }^{-}$and that our method is applicable for further examination of the kinetic features of $\mathrm{NO}_{2}^{-}$in vivo. $-\mathrm{NO}_{2}{ }^{-}$measurement; $\mathrm{NO}_{2}{ }^{-}$contamination; HPLC-Griess system; arterio-venous differences; biological samples.
\end{abstract}

Tohoku J. Exp. Med., 2008, 215 (1), 1-11.

(C) 2008 Tohoku University Medical Press

Nitrite $\left(\mathrm{NO}_{2}^{-}\right)$, a metabolite of nitric oxide (NO), is assumed not only to be a possible index of endothelial NO production, but also to play an important role in regulation of vascular tone as an intrinsic reservoir of nitric oxide (NO). The latter possibility is supported by the fact that nitrite reductase activity of deoxygenated hemoglobin (deoxyHb) catalyzed $\mathrm{NO}_{2}{ }^{-}$to form $\mathrm{NO}$ (Dejam et al. 2004). Indeed, several studies have reported a close relationship among changes in endotheliumdependent blood flow, plasma $\mathrm{NO}_{2}^{-}$levels (Lauer et al. 2001; Kleinbongard et al. 2003, 2006),

Received January 4, 2008; revision accepted for publication March 8, 2008.

Correspondence: Takaharu Ishibashi, M.D., Ph.D., Department of Pharmacology, School of Nursing, Kanazawa Medical University, Uchinada, Ishikawa 920-0293, Japan.

e-mail: ishitaka@kanazawa-med.ac.jp 
enhancement of vasodilatory activity of $\mathrm{NO}_{2}{ }^{-}$and increased production of $\mathrm{NO}$ in the presence of deoxyHb (Cosby et al. 2003; Lundberg and Govoni 2004; Crawford et al. 2006; Grubina et al. 2007; Shiva et al. 2007). Investigating these processes requires accurate and highly sensitive methods for quantifying $\mathrm{NO}_{2}^{-}$, although improving the sensitivity of such techniques also increases the chance of confounding factors that must be excluded. Plasma $\mathrm{NO}_{2}{ }^{-}$level is relatively unaffected by diet or renal function (Lauer et al. 2001;
Kleinbongard et al. 2003) compared with plasma levels of nitrates $\left(\mathrm{NO}_{3}{ }^{-}\right)$(Ishibashi et al. 2000a; Himeno et al. 2003), although the measurement may not necessarily be free from contamination. Measurements are therefore required to minimize possible $\mathrm{NO}_{2}{ }^{-}$contamination from laboratory ware and the environment to accurately determine the level of this ubiquitous substance in biological samples (Ishibashi et al. 2000a; Himeno et al. 2004). Many laboratories have stressed the importance of avoiding contamination in the

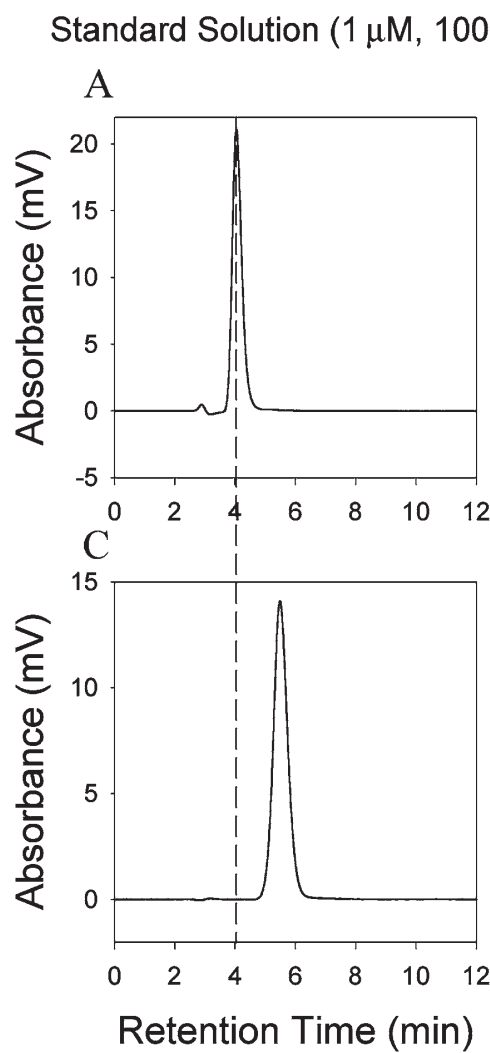

Human Plasma $(100 \mu l)$
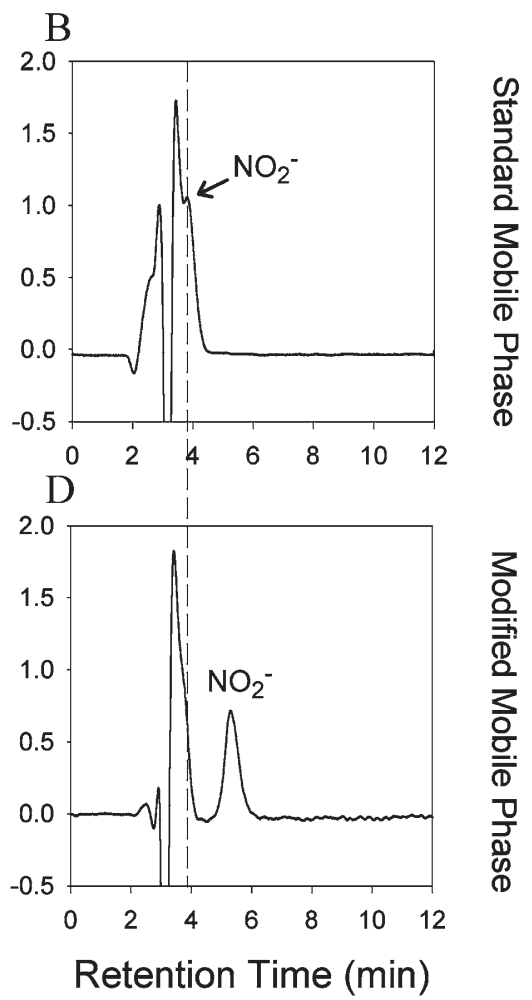

Fig. 1. Prolongation of retention time with modified mobile phase.

Slight modification (changes in concentration of ion pair and $\mathrm{NaCl}$ ) of the mobile phase prolonged retention time of $\mathrm{NO}_{2}^{-}$by about $2 \mathrm{~min}$. This modification is necessary for complete separation of $\mathrm{NO}_{2}{ }^{-}$peak from the front breakthrough for accurate quantification of the subject. A: Peak of $\mathrm{NO}_{2}{ }^{-}$ in standard solution ( $1 \mu \mathrm{M}$ in standard mobile phase, loading volume of $100 \mu \mathrm{l})$ with the standard mobile phase. B: Peak of $\mathrm{NO}_{2}^{-}$in human plasma (loading volume of $100 \mu \mathrm{l}$ ) with the standard mobile phase. Note that overlapping the peak of $\mathrm{NO}_{2}^{-}$with the descending part of the breakthrough makes accurate evaluation of the peak difficult. C: Peak of $\mathrm{NO}_{2}^{-}$in standard solution $(1 \mu \mathrm{M}$ in modified mobile phase, loading volume of $100 \mu \mathrm{l}$ ) with the modified mobile phase. Retention time is prolonged by about $2 \mathrm{~min}$. D: Peak of $\mathrm{NO}_{2}^{-}$in human plasma (the same sample subjected in $\mathrm{B}$, loading volume of $100 \mu \mathrm{l}$ ) with the modified mobile phase. The peak of $\mathrm{NO}_{2}{ }^{-}$is clearly independent and accurate evaluation is possible. Dotted lines indicate retention time of $\mathrm{NO}_{2}^{-}$in the standard solution and human plasma with standard mobile phase to indicate prolongation of retention time with modified mobile phase. 
determination of $\mathrm{NO}_{3}{ }^{-}$(Ishibashi et al. 2000a; Dejam et al. 2004; Tsikas et al. 2006). However, publications dealing with $\mathrm{NO}_{2}^{-}$measurement in biological samples rarely provide such warnings about sample contamination. The present study sought to clarify the origins and extent of $\mathrm{NO}_{2}{ }^{-}$ contamination during biological sample handling and to explore countermeasures for eliminating contamination. In addition, we verified the effectiveness of such measures in specific biological applications.

\section{Materials and Methods}

\section{Measurement of $\mathrm{NO}_{2}^{-}$}

$\mathrm{NO}_{2}^{-}$was quantified using high-performance liquid chromatography (HPLC) on a Griess system (ENO 10

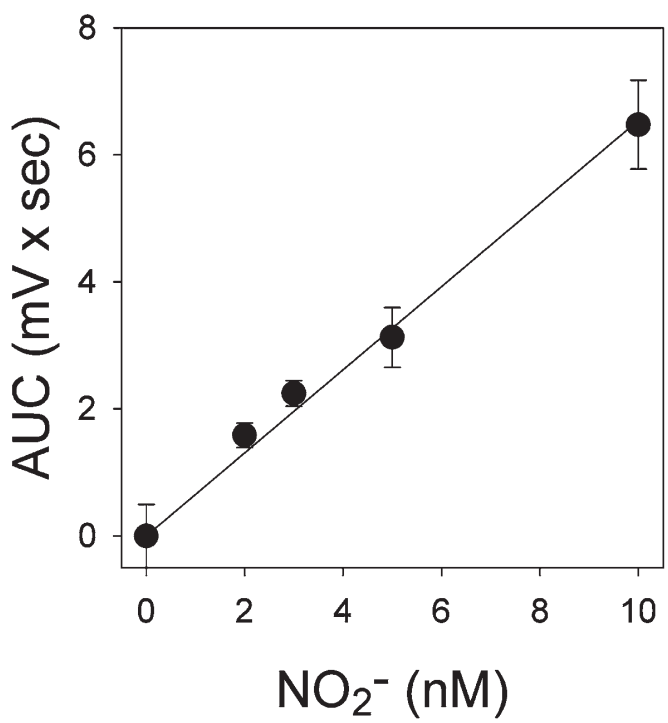

Fig. 2. Standard curve for nanomolar detection of $\mathrm{NO}_{2}^{-}$.

$\mathrm{NO}_{2}^{-}$was dissolved in modified mobile phase and $100 \mu 1$ was loaded into the HPLC-Griess system. Each point represents the mean \pm S.E.M. of three measurements. A significant difference from the blank (mobile phase alone) was recognized at $1 \mathrm{nM}$, although linearity was observed above $2 \mathrm{nM}$ and the difference from $3 \mathrm{nM}$ was statistically significant. To simplify the figure, marks denoting statistical significance were omitted. As the mobile phase itself contains a small, but significant amount of $\mathrm{NO}_{2}{ }^{-}$, AUC (area under curve) of each measurement represents the difference from the mean of the blank control (mobile phase). and ENO 20, Eicom, Kyoto). The system consists of a separation column, a flow reactor (with Griess reagent), reduction column, and a 540-nm detector as described elsewhere (Ishibashi et al. 2000b). The detection limit and sensitivity were both $0.1 \mu \mathrm{M}$ for $\mathrm{NO}_{2}{ }^{-}$with a loading volume of $10 \mu \mathrm{l}$ under the default setup; however, for nanomolar determinations of $\mathrm{NO}_{2}{ }^{-}$, we made two modifications. First, the loading volume was increased to 100 $\mu l$ and the reduction column was removed. Second, the composition of the mobile phase (Yamada and Nabeshima 1997) was slightly modified ( $\mathrm{NaCl}$ was reduced to $2 \mathrm{~g} / \mathrm{L}$ ) to prolong $\mathrm{NO}_{2}^{-}$retention time and ensure complete separation from the front breakthrough when plasma was subjected to quantification (Fig. 1). The modification was because an increased injection volume $(100 \mu \mathrm{l})$ of sample submerged $\mathrm{NO}_{2}{ }^{-}$signal in a larger breakthrough (Fig. 1B). These changes increased the sensitivity and detection limit for $\mathrm{NO}_{2}{ }^{-}$to 1 and $2 \mathrm{nM}$, respectively (Fig. 2).

\section{Human plasma}

Human plasma was drawn into a vacuum bloodsampling tube containing a heparin disk (Venoject H050, Terumo, Tokyo) from five healthy volunteers from the laboratory staff of the Department of Pharmacology, Kanazawa Medical University. Each volunteer gave written informed consent prior to blood sampling. The present study complied with the Declaration of Helsinki and was approved by the Ethics Committee of Kanazawa Medical University.

\section{Animal experiments}

Japanese white rabbits weighing 2.4-3.5 kg were anesthetized with intravenous sodium pentobarbital (30 $\mathrm{mg} / \mathrm{kg}$ ). Cannulae were inserted into the jugular veins (for drug administration), carotid arteries (for monitoring blood pressure), as well as femoral veins and arteries (for blood sampling). Pulse rate was monitored using a tachometer triggered by arterial pressure pulse wave. Experimental procedures were performed after a stabilization period of 20-60 min. First, baseline control blood samples were collected, then after several minutes for recovery of hemodynamic parameters, $500 \mathrm{nmoles} / \mathrm{kg}$ of $\mathrm{NO}_{2}{ }^{-}$or (+/-)-(E)-4-methyl-2-[(E)-hydroxyimino]-5nitro-6-methoxy-3-hexenamide (NOR1, an NO donor agent) was injected intravenously $(0.1 \mathrm{ml} / \mathrm{kg}$ of $5 \mathrm{mM}$ $\mathrm{NaNO}_{2}$ in saline or $5 \mathrm{mM}$ NOR1 in dimethyl sulfoxide [DMSO]), and arterial and venous blood samples were withdrawn $30 \mathrm{sec}$ later. A small volume of the initial 
blood sample (about $0.5 \mathrm{ml}$ ) was used to wash the sampling route (including syringe), and was then discarded to avoid possible contamination of subsequent sample. Then, samples of arterial and venous blood ( $1.5 \mathrm{ml}$ each) were collected. Blood samples were immediately transferred to prewashed microcentrifuge tubes $(1.5 \mathrm{ml}$, QSP, Porex Bio Products Group, Petaluma, CA, USA) each containing a heparin disk (1/4 piece taken from vacuum blood-sampling tubes (Venoject II/VP-H050K, Terumo, Tokyo). Plasma was obtained after centrifugation (1,600 $\times g$ for $5 \mathrm{~min}$ at $4^{\circ} \mathrm{C}$ ), and then mixed with methanol $(1: 1)$ and centrifuged $\left(10,000 \times g\right.$ for $10 \mathrm{~min}$ at $\left.4^{\circ} \mathrm{C}\right)$ to remove proteins. The supernatant was used immediately for $\mathrm{NO}_{2}{ }^{-}$analysis in every experiment. These procedures minimized $\mathrm{NO}_{2}{ }^{-}$and $\mathrm{NO}_{3}{ }^{-}$contamination of the blood samples from laboratory ware and environment.

The Ethics Committee of Kanazawa Medical University approved all animal procedures, and animals were treated under conditions set by the "Guiding Principles for the Care and Use of Laboratory Animals (Japanese Pharmacological Society)".

\section{Reagents}

$\mathrm{NaNO}_{2}$ (Wako Pure Chemical Industries, Osaka) was dissolved in saline (Otsuka Pharmaceutical Factory, Tokushima). NOR1 (Dojindo Laboratories, Kumamoto) was dissolved in DMSO (Wako Pure Chemical Industries, Osaka). All other chemicals were of analytical grade and commercially available. Special attention was paid to the water quality, and only pure water (resistance >18.3 Mohm: MILLI-Q SP; Millipore Co., Bedford, MA, USA) was used following confirmation of low levels of contaminating $\mathrm{NO}_{2}{ }^{-}$and $\mathrm{NO}_{3}{ }^{-}(<10 \mathrm{nM})$.

\section{Statistical analysis}

All data were expressed as mean \pm s.E.M. Within groups differences were compared by using the paired $t$-test while differences between two groups were tested by the unpaired $t$-test. Differences among three or more groups were compared by one-way analysis of variance followed by Fischer's method. Differences were considered significant at a probability value $(p)$ of less than 0.05 .

\section{Results}

It is well known that significant $\mathrm{NO}_{3}$ contamination of samples could occur during the entire measurement procedure (Ishibashi et al. 2000a). In this study, we therefore first assessed possible contamination of our samples with $\mathrm{NO}_{2}^{-}$.
To simulate human blood-sample processing for $\mathrm{NO}_{2}{ }^{-}$determination at nanomolar levels using a butterfly needle, $5 \mathrm{ml}$ of phosphate buffered saline (PBS) was drawn into a vacuum blood-sampling tube containing a heparin disk (Venoject H050, Terumo, Tokyo) and gently agitated by rolling. After centrifugation $\left(1,700 \times g\right.$, for $5 \mathrm{~min}$ at $\left.4^{\circ} \mathrm{C}\right)$, $1 \mathrm{ml}$ of the supernatant was transferred to a microcentrifuge tube for preservation at $-80^{\circ} \mathrm{C}$. A sample of the PBS used for $\mathrm{NO}_{2}{ }^{-}$determination $(0.5 \mathrm{ml})$ was immediately transferred to a new microcentrifuge tube without preservation, and was deproteinized by mixing with $0.5 \mathrm{ml}$ of methanol. The solution was vortexed before centrifugation $\left(10,000 \times \mathrm{g}\right.$, for $10 \mathrm{~min}$ at $\left.4^{\circ} \mathrm{C}\right)$, and the solution (as supernatant) was decanted into another microcentrifuge tube. The solution was then transferred to a sample tube (Gilson, Middleton, WI, USA) from which the analysis aliquot was loaded automatically (Autoinjector 234, Gilson) onto the HPLC-Griess system described above for $\mathrm{NO}_{2}{ }^{-}$determination. As shown in Fig. 3, $\mathrm{NO}_{2}{ }^{-}$ concentration significantly increased by approximately $23 \mathrm{nM}(n=8)$ after the handling procedure. To identify the source of the contamination, $\mathrm{NO}_{2}^{-}$was also measured at every step of the procedure. The use of vacuum blood-sampling tubes had no effect on $\mathrm{NO}_{2}^{-}$concentration. Repeated washing (5 times) of plastic disposable laboratory ware with pure water slightly but significantly (by about $3 \mathrm{nM}$ ) reduced $\mathrm{NO}_{2}{ }^{-}$contamination throughout the whole procedure. The major source of contamination was the deproteinization step. Methanol treatment $(1: 1)$ increased $\mathrm{NO}_{2}{ }^{-}$concentration by an average of $10 \mathrm{nM}$ (Fig. 4), indicating that the methanol used contained $\mathrm{NO}_{2}^{-}$, and this was confirmed by analysis of methanol alone $\left(\mathrm{NO}_{2}{ }^{-}\right.$concentration of $\left.12.6 \pm 1.4 \mathrm{nM} ; n=3\right)$. This level was also found in methanol from other glass bottles regardless of lot number or duration after opening (data not shown).

In another study, we explored the best way to pretreat plasma to minimize $\mathrm{NO}_{2}^{-}$contamination. Ultrafiltration proved unsuitable for this aim; when $1 \mathrm{ml}$ of PBS was ultrafiltered by several different commercially available units, contamination varied from $26 \mathrm{nM}$ to $1,350 \mathrm{nM}$ depending 


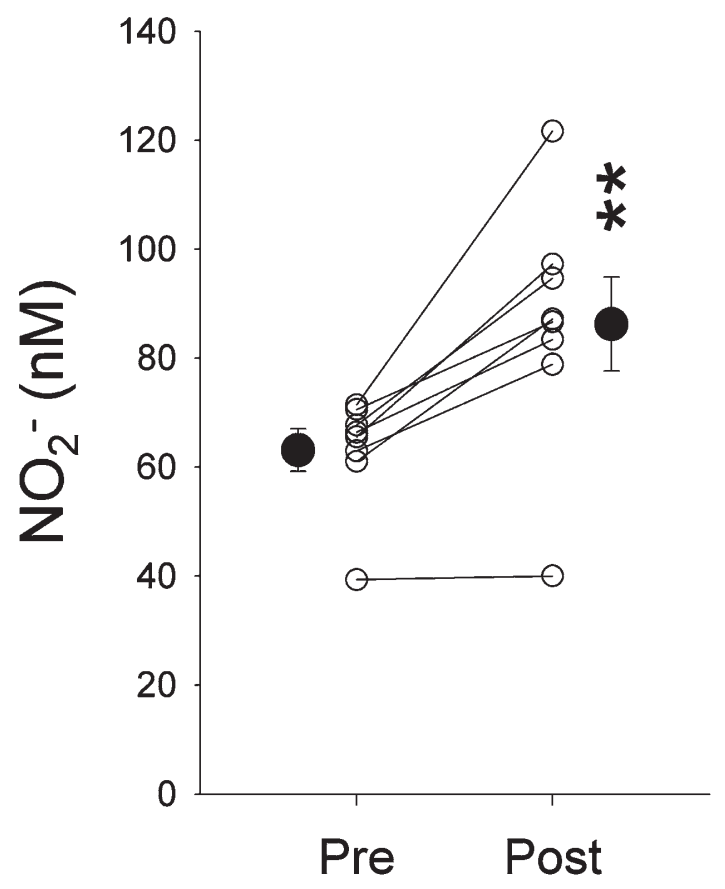

Fig. 3. $\mathrm{NO}_{2}{ }^{-}$contamination throughout the entire sample treatment.

Simulation of the whole procedure using PBS $(0.1 \mathrm{mM}, \mathrm{pH} 7.4)$ as a substitute for blood $(n=$ 8). Open circles: $\mathrm{NO}_{2}{ }^{-}$values in each test, closed circles: mean \pm S.E.M. values. $* * p<$ 0.01 , compared with pretreatment (control). Pre, pretreatment; Post, post treatment.

on manufacturer or filter membrane material used (Figs. 4 and 5). The lowest noise was found with the Centrisart I (Sartrius, Göttingen, Germany), a unique ultrafiltration unit consisting of an outer tube and a sliding inner cylinder fitted with a filter membrane (cut-off of $10 \mathrm{kDa}$, triacetylcellulose) at the bottom. The test sample was placed between the outer tube and the filter membrane of the inner cylinder. Following centrifugation $(1,800 \times g$ for $5 \mathrm{~min})$, the upward filtrate was obtained in the inner cylinder (filtration direction opposite to other common filter units examined). $\mathrm{NO}_{2}{ }^{-}$concentration in the PBS significantly increased from $6.4 \pm 0.8 \mathrm{nM}$ to $32.7 \pm 2.3 \mathrm{nM}$ using this unit $(n=6)$; this increase was about half of that with common units that use the same membrane material, but with downward filtration (increase by about 60 nM, VS [TAC]; Fig. 5). However, the increase was still significantly

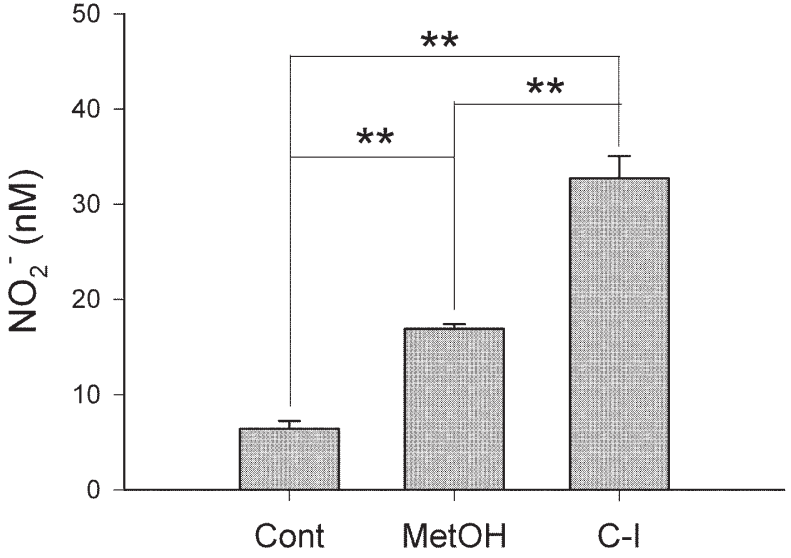

Fig. 4. Increase in $\mathrm{NO}_{2}{ }^{-}$by methanol treatment and ultrafiltration.

PBS (Cont) was subjected to methanol treatment (mixed with methanol in volume of $1: 1$, MetHO) or ultrafiltrated by Centrisart I ( $1 \mathrm{ml}$, $1,800 \times g$ for $5 \mathrm{~min}, \mathrm{C}-\mathrm{I}) .{ }^{*} * p<0.01(n=6$ for each bar).

greater than that associated with methanol treatment (Fig. 4). Methanol mixing was therefore chosen as the preferred pretreatment of plasma for deproteinization prior to $\mathrm{NO}_{2}^{-}$measurement. Unless otherwise mentioned, all laboratory ware was washed 5 times with pure water to minimize not only $\mathrm{NO}_{2}{ }^{-}$, but also $\mathrm{NO}_{3}{ }^{-}$contamination.

Next, we evaluated possible $\mathrm{NO}_{2}^{-}$contamination from room air. As shown in Fig. 6, tubes left open to the environment for only $1 \mathrm{hr}$ showed increased $\mathrm{NO}_{2}{ }^{-}$in solution compared to capped tubes, which showed no significant increase within 8 hours regardless of constituents of the gaseous phase in the headspace of the tube: either room air or argon gas. Other possible atmospheric contamination was also examined. The transfer of pure water (about $50 \mathrm{ml}$ ) from the tap of the reservoir to a washed beaker $(200 \mathrm{ml})$ set at 1 and $2 \mathrm{~m}$ below tended to increase $\mathrm{NO}_{2}{ }^{-}$concentration in the solution $(10.6 \pm 2.5 \mathrm{nM}$ at $1 \mathrm{~m}$ below and $11.2 \pm 1.8 \mathrm{nM}$ at $2 \mathrm{~m}$ below), compared with water expelled directly down the wall of the beaker from the tap $(8.5 \pm 2.3 \mathrm{nM} ; n=6$ in each trial), although the difference was not statistically significant. Vigorous sample mixing by vortexing with room air in a microcentrifuge tube $(1.5 \mathrm{ml})$ was another cause for concern. Ten vortexings of 

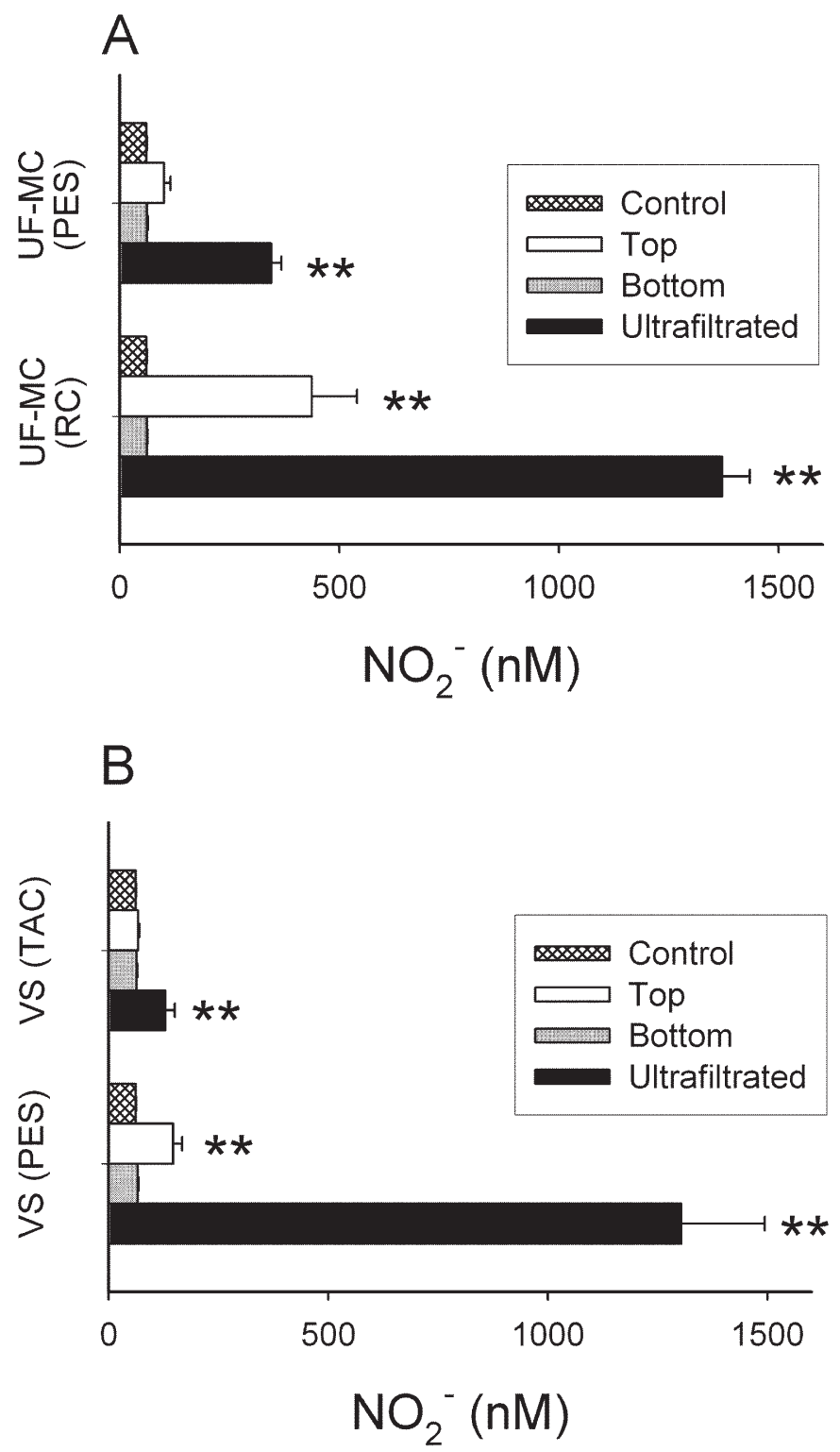

Fig. 5. $\mathrm{NO}_{2}^{-}$contamination by ultrafiltration.

A: Units for small volume. B: Units for large volume.

The following ultrafiltration units with a cut-off of $10 \mathrm{kDa}$ were tested: Ultrafree-MC (UF-MC: Millipore Co., Bedford, MA, USA) for small volumes (A: up to $0.4 \mathrm{ml}$ ) and Vivaspin (VC: Sartorius, Göttingen, Germany) for large volumes (B: up to $2 \mathrm{ml}$ ). All units are of the common type in which the sample is filtered downwards. Control: PBS in a reservoir (before load). Top: PBS (0.4 $\mathrm{ml}$ for small volume, and $1 \mathrm{ml}$ for large volume) only loaded into upper unit (loading device). Bottom: PBS (0.4 ml for small volume, and $1 \mathrm{ml}$ for large volume) only loaded into lower unit (collecting device): Ultrafiltrated: PBS ultrafiltrated $(0.4 \mathrm{ml}$ for $10 \mathrm{~min}$ at 5,000 $\times \mathrm{g}$ in small units and 1 $\mathrm{ml}$ for $10 \mathrm{~min}$ at $1,800 \times g$ in large units) after 5 washes of upper (including surface of filter) and lower units. Each unit was used without prewash in pure water unless otherwise stated. Each bar represents results of 6 trials, each using new units. $*^{*} p<0.01$, compared with the control (Only this difference is indicated in the figure to simplify the graphic presentation). Material of the filter is indicated in parenthesis. TAC, triacetylcellulose; RC, regenerated cellulose; PES, polyethersulfone. 


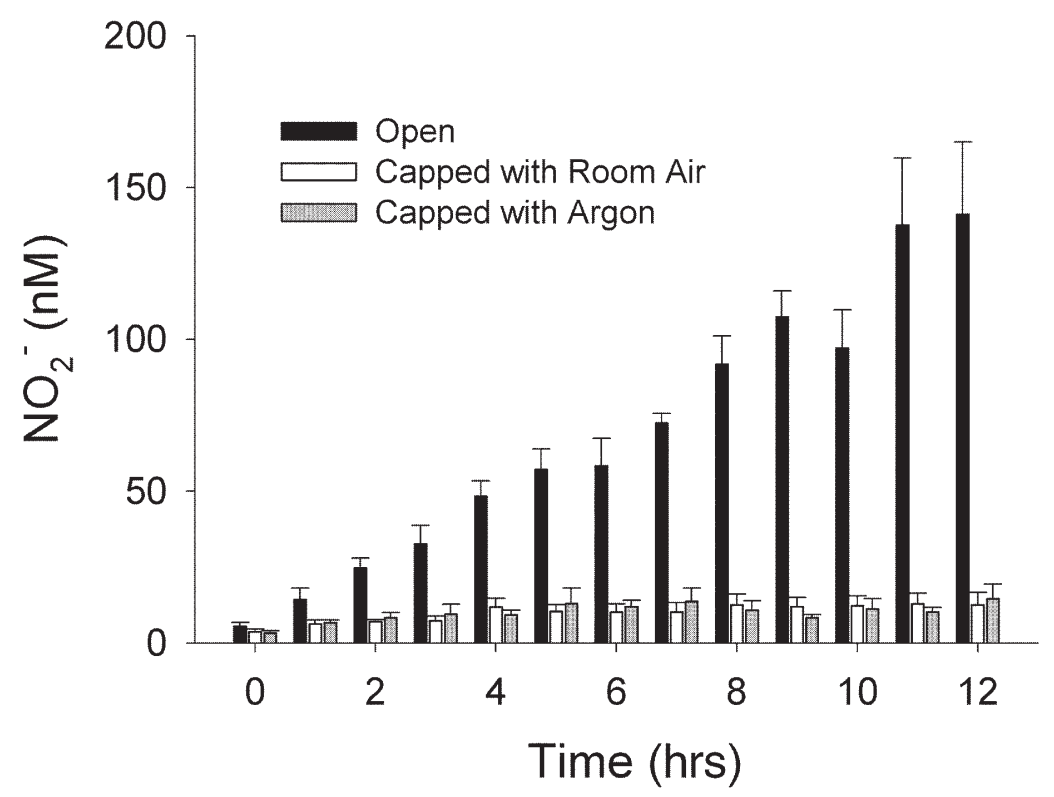

Fig. 6. $\mathrm{NO}_{2}{ }^{-}$contamination from room air.

Sampling tube for automated sampler $(1 \mathrm{ml})$ with $0.18 \mathrm{ml}$ of PBS $(0.1 \mathrm{mM}$, pH 7.4) was left open to room air or capped with or without flushing the headspace with argon gas. These samples were kept at $4{ }^{\circ} \mathrm{C}$ for the indicated period and $\mathrm{NO}_{2}{ }^{-}$was determined. $\mathrm{NO}_{2}{ }^{-}$levels in tubes exposed to room air were significantly higher than in those capped with either room air or argon gas in headspace after $1 \mathrm{~h}$. However, no significant increases were observed in $\mathrm{NO}_{2}^{-}$levels in tubes capped with room air at up to $8 \mathrm{hrs}$. Marks denoting the statistical differences were not presented in the figure to simplify the graphic presentation ( $n=4$ for each bar).

PBS $(0.5,1.0$, and $1.5 \mathrm{ml})$ for $30 \mathrm{sec}$ each separated by 30 -sec intervals during which the lids were kept open to exchange air of the head space did not increase $\mathrm{NO}_{2}^{-}$level significantly in comparison to those not vortexed at all $(n=8$ for each trial and for control; data not shown). Increasing the total number of vortex sequences (vortex 30 sec followed by air exchange $30 \mathrm{sec}$ ) by 5,10 , and 20 times had no significant effect on $\mathrm{NO}_{2}{ }^{-}$ levels compared to unvortexed controls $(n=8$ in each trial and control; data not shown).

Based on these preliminary experiments, we avoided exposure of samples to the open room air whenever possible. We then applied the described optimizations to processing of biological samples from human and anesthetized rabbits.

First, we quantitatively compared $\mathrm{NO}_{2}^{-}$signals from the same human plasma sample under different separation conditions (with default mobile phase or modified mobile phase) because the modified mobile phase showed a $\mathrm{NO}_{2}{ }^{-}$signal that was independent of the initial breakthrough (Fig. 1). The estimated concentration of $\mathrm{NO}_{2}^{-}$in human venous plasma with a modified mobile phase $(92 \pm 33 \mathrm{nM})$ was significantly $(p<0.05$, $n=5$ ) higher than in samples with a default mobile phase $(70 \pm 29 \mathrm{nM})$.

Using this highly sensitive procedure on rabbit plasma, we detected a small (by approximately $93 \mathrm{nM}$, mean) but significant arterio-venous difference in $\mathrm{NO}_{2}^{-}$level under control conditions in a small number of samples (Fig. 7A, $n=6$ ). Intravenous injection of $\mathrm{NaNO}_{2}(500 \mathrm{nmoles} / \mathrm{kg}$ body weight) significantly increased the plasma $\mathrm{NO}_{2}^{-}$levels in both arterial and venous blood $(p<$ $0.01)$. The arterio-venous difference became more prominent after the $\mathrm{NaNO}_{2}$ load; the arterial level was markedly higher than the venous level despite the intravenous injection (Fig. 7B). Under this condition, there were no significant changes in heart rate (control: $288.2 \pm 13.4, \mathrm{NaNO}_{2}: 288.2$ \pm 13.6 beats $/ \mathrm{min}$ ) or mean blood pressure (control: 

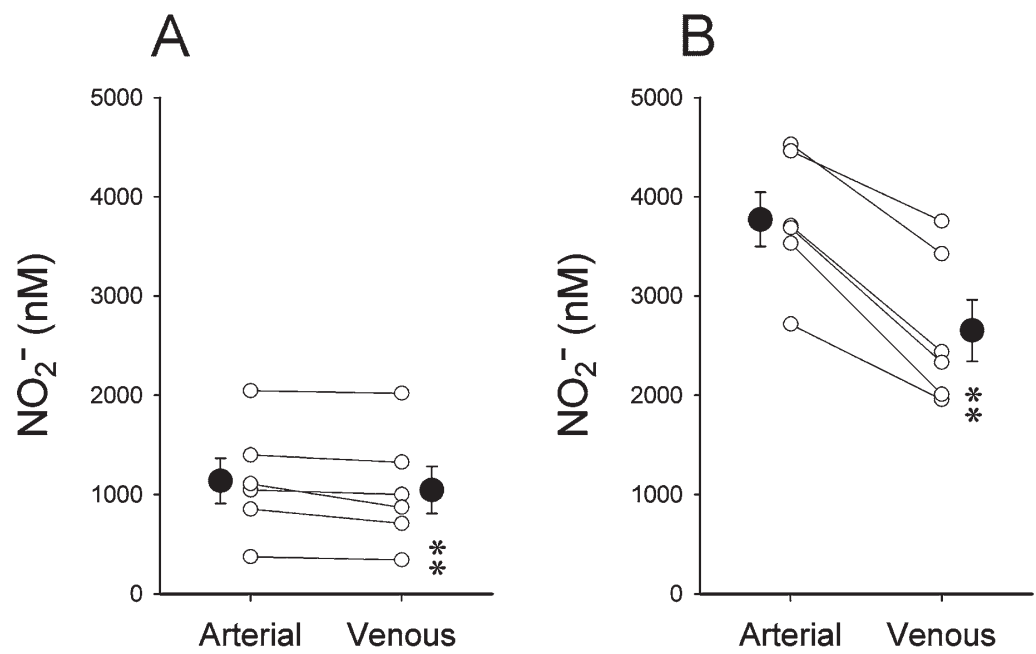

Fig. 7. Arterio-venous differences in $\mathrm{NO}_{2}{ }^{-}$concentration in rabbit plasma.

$\mathrm{NO}_{2}^{-}$levels evaluated before (A) and $30 \mathrm{sec}$ after (B) intravenous administration of $\mathrm{NaNO}_{2}(500$ nmoles $/ \mathrm{kg})$ in 6 rabbits $(2.8 \pm 0.1 \mathrm{~kg})$. Open circles: Data of individual rabbits, closed circles: group mean \pm S.E.M. values. Arterial, Arterial blood; Venous, Venous blood. $* * p<0.01$ (paired $t$-test), compared with arterial blood levels. Increases in $\mathrm{NO}_{2}^{-}$levels in both arterial and venous blood after $\mathrm{NaNO}_{2}$ injection were significant $(p<0.01)$, however, marks denoting significance are not included to simplify the graphic presentation.

$\left.107.2 \pm 4.5, \mathrm{NaNO}_{2}: 107.3 \pm 4.2 \mathrm{mmHg}\right) . \quad$ In another set of tests $(n=5)$, intravenous injection of NOR1 (500 nmoles/kg) significantly $(p<0.05)$ decreased blood pressure by $54.1 \pm 1.3 \mathrm{mmHg}$ (control: $102.0 \pm 3.1$, NOR1: $47.9 \pm 2.5 \mathrm{mmHg}$ ) without changes in heart rate (control: $312.8 \pm 7.6$, NOR1: $315.4 \pm 9.7$ beats $/ \mathrm{min})$ after $30 \mathrm{sec}$. Concomitant increase in arterial $\mathrm{NO}_{2}{ }^{-}$concentration by $111 \pm 7 \mathrm{nM}$ (control: $201 \pm 32$, NOR1: $312 \pm 36 \mathrm{nM})$ was significantly $(p<0.05)$ greater than in venous $\mathrm{NO}_{2}^{-}$concentration by $28 \pm 8 \mathrm{nM}$ (control: $179 \pm 24$, NOR1: $208 \pm 25 \mathrm{nM} ; p<0.05$ ).

\section{DiscuSSION}

In this study, modifications to the quantification setup and mobile phase of the HPLC system used to measure $\mathrm{NO}_{2}{ }^{-}$concentrations in solution achieved complete separation of the signal peak of $\mathrm{NO}_{2}{ }^{-}$from the front breakthrough and increased the sensitivity to $\mathrm{nM}$ levels $(>2 \mathrm{nM})$. This technical improvement would allow for more accurate quantification of $\mathrm{NO}_{2}^{-}$in biological samples. Our detection limit was lower than the $30 \mathrm{nM}$ achieved by another HPLC technique (Smith et al. 2002), the $10 \mathrm{nM}$ by flow-injection analysis
(Kleinbongard et al. 2006), and the $100 \mathrm{nM}$ by electron spin resonance (Minakata et al. 2004), and is comparable to the $1 \mathrm{nM}$ limit reported using reduction chemiluminescence (Feelisch et al. 2002) or another HPLC technique (Rassaf et al. 2002). Our results clearly demonstrated that complete separation of the $\mathrm{NO}_{2}{ }^{-}$signal from the sleeve of the front breakthrough led to significantly higher plasma $\mathrm{NO}_{2}^{-}$levels and indicated the importance of the present conditions for accurate quantification of the signal.

We found here that the degree of $\mathrm{NO}_{2}{ }^{-}$ contamination during sample processing is not a serious problem in comparison to our previous findings on $\mathrm{NO}_{3}{ }^{-}$contamination (Ishibashi et al. 2000a). In particular, $\mathrm{NO}_{2}{ }^{-}$contamination from laboratory ware was virtually negligible except if using ultrafiltration units. We carefully selected a vacuum blood-sampling tube for minimum contamination according to our previous experience (Ishibashi et al. 2000a), however it is still worth noting that many sampling tubes available for clinical use are contaminated with both $\mathrm{NO}_{3}{ }^{-}$and $\mathrm{NO}_{2}{ }^{-}$to varying degrees (Tsikas et al. 1997; Ishibashi et al. 2000a). 
One reason for the low level of contamination during sample handling in our protocol may be the avoidance of glassware known for persistent contamination (Ishibashi et al. 2000a; Smith et al. 2002). Problems can be encountered during deproteinization to remove proteins and large particles before loading of samples (plasma) on the HPLC-Griess and other systems. This procedure is necessary, however, to protect the column and to avoid pressure build-up in the system. Ultrafiltration units are commonly used for deproteinization; however, such units are a potential source of significant $\mathrm{NOx}$ (not only $\mathrm{NO}_{3}^{-}$, but also $\mathrm{NO}_{2}{ }^{-}$) contamination (Ishibashi et al. 2000a; Smith et al. 2002). Although $\mathrm{NO}_{2}{ }^{-}$contamination below $30 \mathrm{nM}$ was reported with some units (Smith et al. 2002), precise determination of $\mathrm{NO}_{2}{ }^{-}$at $\mathrm{nM}$ level requires even lower detection limits. Our study found the lowest contamination with the Centrisart I unit, in agreement with a previous report (Tsikas et al. 1997). However, the level was not negligible and might vary among units, leading to inaccurate evaluation. An alternative is the use of methanol for deproteinization. This study showed that methanol per se contains low levels of $\mathrm{NO}_{2}{ }^{-}$, and was associated with the lowest increase in $\mathrm{NO}_{2}^{-}$. We therefore recommend methanol as the best option for deproteinizing samples at present. Samples in one experimental series or from one individual should be treated at the same time to avoid varying degrees of $\mathrm{NO}_{2}{ }^{-}$contamination.

Contamination of $\mathrm{NO}_{2}^{-}$from the environment is time-dependent and can be serious. To minimize such contamination, we recommend restricting sample contact with the atmosphere using gas-tight ware wherever possible. We found that repeated vortexing of samples, with opening of tube caps to exchange air of the headspace before every vortex, did not increase $\mathrm{NO}_{2}$ levels significantly, However, this kind of vigorous agitation should be kept to a minimum to avoid any risk of atmospheric contamination. It is advisable to use sample containers that have minimal headspace for the same reason, and one should be more cautious when samples are handled in an environment nearby heavy traffic or a high density of factories. Furthermore, the use of flame or fire originating from liquid or gaseous fuel nearby may cause heavy contamination and preclude accurate evaluation (personal communication from a technical staff member of Eicom, Kyoto).

The same issue of atmospheric contamination should be considered for all solutions used in the HPLC-Greiss system. Wide and long bottle openings (mobile phase and Griess reagent) may increase $\mathrm{NO}_{2}^{-}$levels, and hence the baseline absorbance value; this may negatively deflect the spectra for samples of significantly lower $\mathrm{NO}_{2}{ }^{-}$ concentrations. Our countermeasure to this problem is restricting the inflow of the air to equal the outflow (rate of pumping), thereby avoiding unnecessary turbulence through the small injection needle and exchange of air in the headspace of the bottles.

By treating blood samples with the measures discussed above, we found clear arterio-venous differences in rabbit plasma $\mathrm{NO}_{2}{ }^{-}$levels. In contrast, an earlier report did not find a significant arterio-venous gradient in plasma $\mathrm{NO}_{2}^{-}$levels sampled from human brachial artery and antecubital vein (Lauer et al. 2001). Based on our findings, this discrepancy may be attributable to $\mathrm{NO}_{2}^{-}$ noise arising from contamination during complex sample handling (use of solutions containing $\mathrm{NaCl}$ and citrate, and ultrafiltration units). Indeed, we already reported higher $\mathrm{NO}_{2}{ }^{-}$levels in human arterial blood from the ascending aorta than in venous blood from the right atrium (Ishibashi et al. 2003), and this agreed with another report evaluating human blood samples from brachial artery and antecubital vein (Gladwin et al. 2000; Cannon et al. 2001). In addition, the arterio-venous gradient was more prominent when $\mathrm{NO}_{2}^{-}$, as well as NO itself by using NOR1, a NO releasing agent (Kato et al. 1996), was administered. The possible significance of such a gradient is under debate. One suggestion is that $\mathrm{NO}_{2}{ }^{-}$ supplies NO for the peripheral micorcirculation, which is rich in deoxyHb and therefore able to reduce $\mathrm{NO}_{2}{ }^{-}$to $\mathrm{NO}$ via nitrite reductase activity (Grubina et al. 2007).

A previous report indicated that plasma $\mathrm{NO}_{2}{ }^{-}$ 
decreased more rapidly when exogenously administered $\mathrm{NO}_{2}^{-}$was incubated with venous blood than with arterial blood (Wennmalm et al. 1993). Consistent with this finding was the demonstration that coexistence of deoxyHb (hypoxia) and nitrite generates NO (Deem et al. 2007; Shiva et al. 2007). NO may contribute to steady-state hemodynamics by activating guanylate cyclase in vascular smooth muscle, and the fate of the NO could be oxidation to $\mathrm{NO}_{2}{ }^{-}$or $\mathrm{NO}_{3}{ }^{-}$. However, no increase in $\mathrm{NO}_{2}^{-}$was observed here in venous plasma. It is reported that NO under this circumstance could be stabilized as nitrosohemoglobin, leading to a decrease in plasma $\mathrm{NO}_{2}{ }^{-}$(Kruszyna et al. 1987). The possible reaction of NO with deoxyHb to form iron-nitrosyl-hemoglobin, a highly stable adduct (Grubina et al. 2007), would contribute to the decrease.

Extremely high doses of $\mathrm{NO}_{2}{ }^{-}(10 \mathrm{mg} / \mathrm{kg}$ body weight of $\mathrm{NaNO}_{2}$, corresponding to 145 $\mu$ moles/kg body weight) decrease blood pressure in anesthetized animals (Blood and Power 2007), although the dose used in our study (500 nmoles/ $\mathrm{kg}$ body weight) was not sufficient to cause such an effect. If the balance between NO generation and scavenging capacity of oxygenated hemoglobin is a determinant of $\mathrm{NO}$ availability for vasodilation (Deem et al. 2007), the small amount of $\mathrm{NO}$ from lower $\mathrm{NO}_{2}{ }^{-}$levels would not necessarily decrease blood pressure. In this case, conditions such as inhibition of nitric oxide synthase may be required for development of vasodilation from the smaller doses of $\mathrm{NO}_{2}{ }^{-}$(Rifkind et al. 2007) administered in the present study.

In conclusion, for accurate determination of $\mathrm{NO}_{2}^{-}$in biological samples, care should be taken to minimize possible contamination from laboratory ware, especially ultrafiltration units, although the degree may be much less of a problem than that for $\mathrm{NO}_{3}{ }^{-}$determinations. Potential atmospheric contamination should be avoided also. A slight gradient in arterio-venous $\mathrm{NO}_{2}^{-}$levels was detected in the plasma of a small number of animals when these cautions were carefully observed.

\section{Acknowledgments}

This study was partly supported by a Grant for Promotion of Research (S2005-10) from Kanazawa Medical University, a Grant-in-Aid for Scientific Research from the Ministry of Education, Culture, Sports, Science and Technology of Japan (18590247) and by MEXT. HAITEKU (2004) from Musashino University.

\section{References}

Blood, A.B. \& Power, G.G. (2007) In vitro and in vivo kinetic handling of nitrite in blood: effects of varying hemoglobin oxygen saturation. Am. J. Physiol Heart Circ. Physiol., 293, H1508-H1517.

Cannon, R.O., III, Schechter, A.N., Panza, J.A., Ognibene, F.P., Pease-Fye, M.E., Waclawiw, M.A., Shelhamer, J.H. \& Gladwin, M.T. (2001) Effects of inhaled nitric oxide on regional blood flow are consistent with intravascular nitric oxide delivery. J. Clin. Invest., 108, 279-287.

Cosby, K., Partovi, K.S., Crawford, J.H., Patel, R.P., Reiter, C.D., Martyr, S., Yang, B.K., Waclawiw, M.A., Zalos, G., Xu, X., Huang, K.T., Shields, H., Kim-Shapiro, D.B., Schechter, A.N., Cannon, R.O., III. \& Gladwin, M.T. (2003) Nitrite reduction to nitric oxide by deoxyhemoglobin vasodilates the human circulation. Nat. Med., 9, 1498-1505.

Crawford, J.H., Isbell, T.S., Huang, Z., Shiva, S., Chacko, B.K., Schechter, A.N., Darley-Usmar, V.M., Kerby, J.D., Lang, J.D., Jr., Kraus, D., Ho, C., Gladwin, M.T. \& Patel, R.P. (2006) Hypoxia, red blood cells, and nitrite regulate NOdependent hypoxic vasodilation. Blood, 107, 566-574.

Deem, S., Min, J.H., Moulding, J.D., Eveland, R. \& Swenson, E.R. (2007) Red blood cells prevent inhibition of hypoxic pulmonary vasoconstriction by nitrite in isolated, perfused rat lungs. Am. J. Physiol. Heart Circ. Physiol., 292 , H963-H970.

Dejam, A., Hunter, C.J., Schechter, A.N. \& Gladwin, M.T. (2004) Emerging role of nitrite in human biology. Blood Cells Mol. Dis., 32, 423-429.

Feelisch, M., Rassaf, T., Mnaimneh, S., Singh, N., Bryan, N.S., Jourd'Heuil, D. \& Kelm, M. (2002) Concomitant S-, N-, and heme-nitros(yl)ation in biological tissues and fluids: implications for the fate of NO in vivo. FASEB J., 16, 1775-1785.

Gladwin, M.T., Shelhamer, J.H., Schechter, A.N., Pease-Fye, M.E., Waclawiw, M.A., Panza, J.A., Ognibene, F.P. \& Cannon, R.O., III. (2000) Role of circulating nitrite and $\mathrm{S}$-nitrosohemoglobin in the regulation of regional blood flow in humans. Proc. Natl. Acad. Sci. USA, 97, 1148211487.

Grubina, R., Huang, Z., Shiva, S., Joshi, M.S., Azarov, I., Basu, S., Ringwood, L.A., Jiang, A., Hogg, N., Kim-Shapiro, D.B. \& Gladwin, M.T. (2007) Concerted nitric oxide formation and release from the simultaneous reactions of nitrite with deoxy- and oxyhemoglobin. J. Biol. Chem., 282, 1291612927.

Himeno, M., Ishibashi, T., Nakano, S., Furuya, K., Kigoshi, T., Uchida, K. \& Nishio, M. (2003) A practical procedure for achieving a steady state NOx concentration in plasma: with special reference to the NOx content of Japanese daily food. Tohoku J. Exp. Med., 199, 95-110.

Himeno, M., Ishibashi, T., Nakano, S., Furuya, K., Yoshida, J., Kigoshi, T., Uchida, K. \& Nishio, M. (2004) Implication 
of steady state concentrations of nitrite and nitrate metabolites of nitric oxide in plasma and whole blood in healthy human subjects. Clin. Exp. Pharmacol. Physiol., 31, 591-596.

Ishibashi, T., Himeno, M., Imaizumi, N., Maejima, K., Nakano, S., Uchida, K., Yoshida, J. \& Nishio, M. (2000a) NOx contamination in laboratory ware and effect of countermeasures. Nitric Oxide, 4, 516-525.

Ishibashi, T., Matsubara, T., Ida, T., Hori, T., Yamazoe, M., Aizawa, Y., Yoshida, J. \& Nishio, M. (2000b) Negative $\mathrm{NO}_{3}{ }^{-}$difference in human coronary circulation with severe atherosclerotic stenosis. Life Sci., 66, 173-184.

Ishibashi, T., Himeno, M., Kubota, K., Matsubara, T., Hori, T., Ozaki, K., Yamazoe, M., Aizawa, Y., Yoshida, J. \& Nishio, M. (2003) Decrease in plasma NOx concentration by isosorbide dinitrate, an organic nitrate ester. J. Cardiovasc. Pharmacol., 41, 40-48.

Kato, M., Nishino, S., Ohno, M., Fukuyama, S., Kita, Y., Hirasawa, Y., Nakanishi, I., Takasugi, H. \& Sakane, K. (1996) New reagents for controlled release of nitric oxide. Structure-activity relationships. Bioorg. Med. Chem. Lett., 6, 33-38.

Kleinbongard, P., Dejam, A., Lauer, T., Rassaf, T., Schindler, A., Picker, O., Scheeren, T., Godecke, A., Schrader, J., Schulz, R., Heusch, G., Schaub, G.A., Bryan, N.S., Feelisch, M. \& Kelm, M. (2003) Plasma nitrite reflects constitutive nitric oxide synthase activity in mammals. Free Radic. Biol. Med., 35, 790-796.

Kleinbongard, P., Dejam, A., Lauer, T., Jax, T., Kerber, S., Gharini, P., Balzer, J., Zotz, R.B., Scharf, R.E., Willers, R., Schechter, A.N., Feelisch, M. \& Kelm, M. (2006) Plasma nitrite concentrations reflect the degree of endothelial dysfunction in humans. Free Radic. Biol. Med., 40, 295-302.

Kruszyna, R., Kruszyna, H., Smith, R.P., Thron, C.D. \& Wilcox, D.E. (1987) Nitrite conversion to nitric oxide in red cells and its stabilization as a nitrosylated valency hybrid of hemoglobin. J. Pharmacol. Exp. Ther., 241, 307-313.

Lauer, T., Preik, M., Rassaf, T., Strauer, B.E., Deussen, A., Feelisch, M. \& Kelm, M. (2001) Plasma nitrite rather than nitrate reflects regional endothelial nitric oxide synthase activity but lacks intrinsic vasodilator action. Proc. Natl. Acad. Sci. USA, 98, 12814-12819.

Lundberg, J.O. \& Govoni, M. (2004) Inorganic nitrate is a possible source for systemic generation of nitric oxide. Free
Radic. Biol. Med., 37, 395-400.

Minakata, K., Okamoto, N., Nozawa, H., Watanabe, K. \& Suzuki, O. (2004) Determination of nitrite in biological fluids by use of electron spin resonance. Anal. Biochem., 325, 168-170.

Rassaf, T., Bryan, N.S., Kelm, M. \& Feelisch, M. (2002) Concomitant presence of $\mathrm{N}$-nitroso and $\mathrm{S}$-nitroso proteins in human plasma. Free Radic. Biol. Med., 33, 1590-1596.

Rifkind, J. M., Nagababau, E., Barbiro-Michaely, E., Ramasamy, S., Pluta, R.M. \& Mayevsky, A. (2007) Nitrite infusion increases cerebral blood flow and decreases mean arterial blood pressure in rats: A role for red cell NO. Nitric Oxide, 16, 448-456.

Shiva, S., Huang, Z., Grubina, R., Sun, J., Ringwood, L.A., MacArthur, P.H., Xu, X., Murphy, E., Darley-Usmar, V.M. \& Gladwin, M.T. (2007) Deoxymyoglobin is a nitrite reductase that generates nitric oxide and regulates mitochondrial respiration. Circ. Res., 100, 654-661.

Smith, C.C., Stanyer, L. \& Betteridge, D.J. (2002) Evaluation of methods for the extraction of nitrite and nitrate in biological fluids employing high-performance anion-exchange liquid chromatography for their determination. J. Chromatogr. B Analyt. Technol. Biomed. Life Sci., 779, 201-209.

Tsikas, D., Gutzki, F.M., Rossa, S., Bauer, H., Neumann, C., Dockendorff, K., Sandmann, J. \& Frolich, J.C. (1997) Measurement of nitrite and nitrate in biological fluids by gas chromatography-mass spectrometry and by the Griess assay: problems with the Griess assay--solutions by gas chromatography-mass spectrometry. Anal. Biochem., 244, 208-220.

Tsikas, D., Gutzki, F.M. \& Stichtenoth, D.O. (2006) Circulating and excretory nitrite and nitrate as indicators of nitric oxide synthesis in humans: methods of analysis. Eur. $J$. Clin. Pharmacol., 62, Suppl. 1, 51-69.

Wennmalm, Å., Benthin, G., Edlund, A., Jungersten, L., KielerJensen, N., Lundin, S., Westfelt, U.N., Petersson, A.S. \& Waagstein, F. (1993) Metabolism and excretion of nitric oxide in humans. An experimental and clinical study. Circ. Res., 73, 1121-1127.

Yamada, K. \& Nabeshima, T. (1997) Simultaneous measurement of nitrite and nitrate levels as indices of nitric oxide release in the cerebellum of conscious rats. J. Neurochem., 68, 1234-1243. 